REVISTA DE DERECHO UNED, NÚM. 14, 2014

\title{
EL CABILDO ABIERTO EN COLOMBIA
}

\author{
THE CABILDO ABIERTO IN COLOMBIA
}

\author{
Ángela María Alvarado Beltrán \\ Candidata a Doctor UNED
}

Resumen: Este artículo sobre el Cabildo Abierto, destaca la importancia que le dio la actual Constitución Colombiana a la participación ciudadana, ya que instauro los mecanismos de participación; hablo sobre su concepto, su paso de institución a mecanismo y sus bases tanto democráticas como jurídicas; este mecanismo podría llegar a tener gran importancia, pero aún falta mucho por avanzar tanto en su desarrollo normativo, como en el afianzamiento de este entre los ciudadanos, para que llegue a ser verdaderamente efectivo entre la población.

Palabras clave: Constitución Política de Colombia. Participación Ciudadana. Cabildo Abierto.

Abstract: This article on the Open Meeting, highlights the importance that gave the current Colombian Constitution to citizen participation, since I instill participation mechanisms, in this short space only speak about its concept, its passage institution mechanism and its bases both democratic and legal, this mechanism could potentially have great importance, but still a long way to go both in policy development and in the strengthening of this among the citizens, for it to become truly effective in the population.

Key words: Political Constitution of Colombia. Citizen Participation. Open Meeting.

Sumario: 1. Concepto de Cabildo Abierto. 2. De Institución a Mecanismo de Participación Ciudadana. 3. Bases del Cabildo Abierto.

Recepción original: 29/04/2014

Aceptación original: 30/05/2014

(C) UNED. Revista de Derecho UNED, núm. 14, 2014 
La Constitución Política de Colombia de 1991, dio un paso más para la participación de los ciudadanos en la vida política, esta se dio por la necesidad del pueblo, permitiendo un acercamiento entre ciudadanos-Estado, ya que les proporciona mecanismos con los cuales poder optar a una mayor participación, y así poder intervenir en las decisiones que los afecten, para la resolución de conflictos entre Estado y sociedad en las decisiones políticas del país, combatiendo así el poco sentido de pertenencia de los ciudadanos y por lo tanto profundizando en el proceso democrático en Colombia, los constituyentes hicieron de la participación un punto primordial, que debía ser avalado por el Estado, por lo tanto se creó la Ley 134 de 1994 «Ley de participación ciudadana» reguladora de estos mecanismos.

\section{CONCEPTO DE CABILDO ABIERTO}

Mecanismo de participación ciudadana reconocido en la Constitución Política de Colombia de 1991 con un gran sentido democrático, y desarrollado en la Ley 134 de 1994 reguladora de los mecanismos de participación, (arts. 9, 81 y siguientes) basado en la unión y participación de un grupo de ciudadanos que de manera organizada soliciten la realización de un Cabildo Abierto a uno de los diferentes entes territoriales con esta competencia, los concejos municipales o distritales o las juntas administradoras locales (JAL), los cuales dentro de su periodo deben realizar al menos dos sesiones a esta petición de Cabildo Abierto que hacen los ciudadanos, para que sean escuchadas sus inquietudes y problemas que son de interés para la comunidad que lo solicita y puedan ser debatidas.

\section{DE INSTITUCIÓN A MECANISMO DE PARTICIPACIÓN CIUDADANA}

El Cabildo a lo largo de la historia se ha ido transformando, inicialmente fue una institución de representación, dio paso al origen de las revueltas que culminaron en la independencia, sobresaliendo la unión del pueblo, que fue lo que a la postre produjo (la unión por intereses comunes) que se diera el Cabildo Abierto, por lo tanto siempre ha tenido caracteres democráticos (hoy en día la unión de parte de los ciudadanos es uno de los requisitos para poder realizar un Cabildo Abierto). A partir de 1840 el cabildo cerrado y el cabildo abierto se transforman en la institución del concejo municipal, con miembros elegidos popularmente, cuya función era velar por los intereses de los 
habitantes del municipio, posteriormente en la constitución de 1886 paso a llamarse Concejo y en la Constitución Política de 1991 toma la forma y esencia que tiene actualmente convirtiéndose en un mecanismo de participación ciudadana.

\section{Aparte de las Capitulaciones:}

Durante la revolución comunera, la práctica del cabildo abierto es revivida, en forma que conduce a las gentes de «ciudades, villas, parroquias y pueblos a que unánimes y todos juntos como una voz de uno solicitas en la quitación de pechos y minorías de excesos que insoportablemente padecía este mísero reino» (Preámbulo de las Capitulaciones). «significaba que el pueblo en uso de su capacidad deliberante y soberana habría de nombrar directamente las nuevas autoridades del reino. Tal fue la consigna dada a los estudiantes y a las multitudes, de manera que a las ocho de la noche solo se escuchaba en la plaza mayor, un grito unánime salido de miles de gargantas: ¡Cabildo Abierto! Esta consigna, a diferencia de lo que suponen muchos historiadores, constituía una advertencia amenazadora no sólo para las autoridades sino, muy particularmente, para la oligarquía criolla empeñada en que todas las decisiones las tomara privativamente el Cabildo de Santa Fe, sin permitir al pueblo desempeñar otra función que la de mudo espectador de la comedia de los notables». ${ }^{1}$

El cabildo de la colonia era arbitro de los intereses municipales, de él participaban los españoles colonizadores y los criollos mercantilistas interesados en definir algunos tributos, el estatuto de policía local y el régimen de libertades y derechos de la población; actuaba como el órgano de la autonomía local y por el cual los vecinos velaban por la solución de los problemas administrativos, económicos y políticos de la célula municipal. ${ }^{2}$

La Constitución de 1991 presenta un gran aporte a la democracia con el tema de participación ciudadana, en esta se introdujo el Cabildo Abierto entre otros mecanismos, todos referentes a la democracia participativa, para que con ellos los ciudadanos pudieran tener relación directa con el estado, se ven diferentes dificultades y tropiezos para llegar a ellos, la Ley 134 de 1994 los reglamentó, pero aun así falta conocimiento por parte de los ciudadanos para hacer un mayor uso de estos, se deben dar oportunidades de acercamiento, quitar fre-

\footnotetext{
${ }^{1}$ Sentencia C.180 de 1994, Corte Constitucional. Bogotá-Colombia.

${ }^{2}$ El Concejo de Río Negro, Reseña Histórica. (3/06/2013) http://www.concejo.rionegro.gov.co/?q=concejo/resena-historica
} 
nos y trabas y así llegar a tener más participación, usar los mecanismos, avanzar en la Democracia.

Examinamos la baja participación ciudadana que hay en este mecanismo (Cabildo Abierto), mostrando las mayores barreras que se le presentan al ciudadano (desconocimiento, difícil acceso etc.) y así pensar en hacerlo más efectivo y que tenga un mejor desarrollo. Este mecanismo depende de la participación conjunta para discutir problemas de interés común, se presenta en los concejos municipales, distritales o en las juntas administradoras locales, las cuales dentro del periodo de sesiones deben hacer por lo menos dos, sobre los temas presentados por la comunidad.

Hoy el Cabildo Abierto resurge en Colombia formalmente como espacio legítimo para que las personas puedan ejercer a título personal pero en nombre de la comunidad, el cumplimiento de los derechos fundamentales frente al Estado, complementando o ampliando las formas de participación políticas propias de la democracia representativa. Para Giovanni Sartori, la democracia participativa consiste en el acto con que cuenta un individuo para incluirse voluntariamente por cuenta propia y no por mandato de otros, de forma directa y personal en actos decisorios. ${ }^{3}$

Son importantes también para tener toda la opinión de los ciudadanos que se interesan en participar, encontrando un instrumento al que recurrir para pedir por sus necesidades, y por otra parte ver las respuestas de concejales y juntas administradoras locales, interactuando para ver así el cumplimiento y utilidad de las mismas, es un mecanismo que esta para que los ciudadanos puedan pedir un mayor cumplimiento de sus derechos.

El Cabildo Abierto se constituye en una salida democrática a la crisis estructural en un mundo de libertades donde la democracia representativa termina siendo insuficiente para atender las aspiraciones de los pueblos con sus problemas reales. ${ }^{4}$

La participación como se ha dicho se ha convertido en esta constitución en base fundamental, ya que ha servido de inspiración del marco en el que se estructura el sistema constitucional de Colombia, por lo tanto el elegir y ser elegido a dado un paso más y se le ha sumado el derecho a participar más activamente en la conformación,

${ }^{3}$ Cogollos, Silvia-Ramírez LeÓn, Jaime, (2007) «El camino tortuoso de la participación ciudadana. Una mirada al cabildo abierto en Bogotá» Bogotá-Colombia universitas humanística n. ${ }^{\circ} 63$, p. 3 .

${ }^{4}$ Ibídem p. 7. 
ejercicio y control del poder político, fortaleciendo la democracia participativa como se plasma en el artículo 103 de la constitución política de 1991 que consagra el conjunto de mecanismos de participación ciudadana, para que todos tengan acceso a la toma de decisiones, llevando a cabo así el Estado Democrático de Derecho, haciendo un control político sin intermediarios, aportando más medios de expresión y vías de solución de los conflictos.

Del fortalecimiento del Cabildo Abierto con su espacio propio, depende la expansión de la modalidad de participación directa en forma de asambleas generales a otros ámbitos del Estado. El Cabildo Abierto, como nos enseña la historia, cuando adquiere dinámica, se convierte en escenario del tratamiento popular a los problemas nacionales, regionales o locales, según el caso. En este punto la Corte pone de presente que la connotación eminentemente deliberante del cabildo que figura en la definición, en modo alguno significa que el legislador haya circunscrito sus efectos. Por el contrario, puede en todo tiempo conferirle capacidad decisoria. Queda, pues, abierta la puerta para que en el futuro, el Congreso por la vía estatutaria le reconozca fuerza vinculante a las deliberaciones populares en cabildo, en forma congruente con la potestad soberana del pueblo quien, como titular originario la ejerce por esta vía de manera directa. Su propósito esencial es ampliar los escenarios de participación de los ciudadanos y en concreto, que la comunidad política de manera directa y pública, intervenga y decida acerca de los asuntos propios de la respectiva población. ${ }^{5}$

\section{BASES DEL CABILDO ABIERTO}

\section{Democráticas}

La historia muestra como la democracia se percibía de manera diferente, como si fuera un concepto de libertad, de sociedad, luego se volvió más hacia el individuo en particular, ya que un estado democrático debe contar con la participación de los ciudadanos para que estos se manifiesten sobre los problemas que los afectan en común y puedan participar en la toma de decisiones, de acá la democracia participativa que surge como solución a las demandas del pueblo, es reglamentada, por lo tanto de uso libre a quienes corresponda según el caso.

\footnotetext{
${ }^{5}$ Sentencia C-180 de 1994. Corte Constitucional. p. 6.
} 
Kaplan afirma que la movilización, las turbulencias sociales y las demandas de participación democrática encuentran respuestas restrictivas y represivas. Así se mantiene el sometimiento de la población a una estructura piramidal de dominación, en la cual los grupos mayoritarios son subordinados a los centros de poder del Estado y hacia núcleos concentrados de poder privado. En este contexto el prototipo vigente del súbdito prevalece sobre el prototipo inexistente o débil del ciudadano, lo desplaza o lo imposibilita. ${ }^{6}$

La democracia como forma de gobierno es antigua. El pensamiento griego legó una tipología de las formas de gobierno, de las cuales una es la democracia, definida esta como el gobierno de muchos, de la mayoría o de los pobres (de los pléthos, la masa). A lo largo de los siglos y de todas las discusiones que han versado sobre la diferencia de la democracia de los antiguos y de los modernos, el termino en general descriptivo no ha cambiado; no ha cambiado el titular del poder político, que siempre es el pueblo, el cual se entiende como el conjunto de los ciudadanos a lo que les toca en última instancia el derecho de tomar las decisiones colectivas, lo que ha cambiado a lo largo de los años y hasta nuestros días ha sido la manera, amplia o restringida, de ejercer este derecho. ${ }^{7}$

La Democracia se basa en los derechos humanos, en defender a los ciudadanos, esto ya se veía de una u otra manera desde antes de la Constitución Política de 1991, la unión de los ciudadanos y su gobierno, hacen que no se centre el poder solo en manos de él, haciéndolo más democrático, siempre han sido los ciudadanos los actores más importantes en el desarrollo de la sociedad, y en esta constitución se ha repetido en varias ocasiones, se dio un gran paso incluyendo los mecanismos de participación ciudadana que luego fueron regulados por la Ley 134 de 1994.

La representación de la democracia ha cambiado desde el siglo XVIII. Primero habíamos definido la democracia por la soberanía del pueblo y la destrucción de un antiguo régimen fundado en la herencia, el derecho divino y los privilegios. La democracia se confundió entonces con la idea de nación, especialmente en Estados Unidos y en Francia. Pero el temor de una dictadura nacional revolucionaria semejante al terror en Francia, y sobre todo el creciente predominio de los problemas económicos sobre los objetivos políticos reemplazaron

\footnotetext{
${ }^{6}$ Marcos Kaplan. (2002). «Estado y Globalización». Universidad Nacional Autónoma de México. p. 366

${ }^{7}$ Norberto Bobbio. (2000). «Liberalismo y Democracia». México: Fondo de Cultura Económica. p. 33
} 
en el siglo XIX la idea de soberanía popular por el concepto de un poder que estuviera el servicio de los intereses de la clase más numerosa. De manera más general la democracia se hizo representativa y sus principales teorizadores hicieron de la democracia un criterio central de la libertad del hombre moderno. ${ }^{8}$

Bobbio cree que la democracia tiene dos significados preponderantes: el conjunto de reglas cuya observancia es necesaria con el objeto de que el poder político sea distribuido efectivamente entre la mayor parte de los ciudadanos; y el ideal de igualdad, en el que un gobierno democrático debería inspirarse. Con base en esta distinción, se suele diferenciar la democracia formal de la democracia sustancial. ${ }^{9}$

Robert Dahl ve la democracia como un conjunto de procedimientos y condiciones por medio de los cuales la población puede elegir a sus gobernantes, afirma que esto no garantiza un buen gobierno, sino la escogencia de lo que quieren las mayorías pudiendo estas equivocarse, al respecto expresa: «Con democracia siempre existirá la posibilidad de cambiarlo en las próximas elecciones o mediante algún mecanismo de participación político alternativo como la revocatoria del mandato. Sin democracia no habría posibilidades de dicho cambio ya que el gobierno sería impuesto ${ }^{10}$

La normativa de los mecanismos de participación es cada vez más acertada, fue diseñada para ayudar a los ciudadanos a que se acerquen más al Estado, está estructurada dentro del concepto de democracia ofreciendo participación al pueblo, la cual es cambiante, creciente, y en constante evolución, pero en la práctica no es del todo así para el Cabildo Abierto, las falencias que presenta la ley, la desigualdad, la falta de compromiso y cumplimiento real son los mayores problemas, nos lleva en retroceso pues no se desarrolla de la mejor manera, influyendo a la deslegitimación del Estado dando paso a mayores crisis de gobierno y sociedad, que inevitablemente siempre están latentes.

Los mecanismos de participación democrática se quedan cortos para los problemas que hay, ya sea por su poco uso, por su mala reglamentación o porque hay poca información sobre todos ellos y esto hace que se dificulte su acceso tanto como debiera ser. Frente a todo esto lo que se ve es que tendrían que existir mayores espacios de par-

${ }^{8}$ Cogollos, Silvia-Ramírez LeÓn, Jaime (2007), «El camino tortuoso de la participación ciudadana». p. 4. Una mirada al cabildo abierto en Bogotá universitas humanística no.63 enero-junio de 2007 Bogotá - Colombia.

${ }^{9}$ Ibídem. p. 4.

${ }^{10}$ Ibídem. p. 5. 
ticipación, afianzando los mecanismos ya existentes, haciéndolos más cercanos y efectivos.

\section{Jurídicas}

Una de las innovaciones de la Constitución Política de 1991, son los mecanismos de participación ciudadana, abrieron paso a una democracia participativa como nueva forma para que los ciudadanos intervengan en asuntos que los afecten, pudiendo ejercer una clase de control político ya que mediante estos pueden pedir citaciones, y respuesta por parte de entidades, organismos y en general. En la Constitución se dejó el tema abierto, a manera de pretensiones que luego la ley 134 de 1994 reglamentó, pero con muchas falencias siendo las principales para el Cabildo Abierto la dificultad de acceder a él y la falta de obligatoriedad en los compromisos que se hacen en los mismos por parte de las autoridades asistentes.

La Constitución abrió nuevos espacios de participación ciudadana, rompió el estrecho marco de la llamada democracia representativa, avanzó al definir el Estado como una Democracia Participativa; pero no ha podido superar el formalismo retórico. En tal sentido, la convivencia pacífica, la tolerancia ideológica, el respeto mutuo, el pleno reconocimiento de las libertades y la igualdad jurídica siguen siendo un ideal político, a pesar de estar consagrados en la norma; lo que hace pensar en la necesidad de un nuevo pacto social que incorpore nuevos elementos a la carta fundamental. ${ }^{11}$

De los 380 artículos consagrados en la Constitución tan sólo 33 están destinados a tratar el tema de la participación política, es decir, el 9 por ciento: artículos 38, 39, 40, 45, 49, 57, 60, 64, 68, 78, 79, 103, $104,105,106,112,154,155,170,242,246,258,260,270,318,329$, $330,340,369,374,375,376,377$. Y en los casos más importantes se utilizan términos como «La ley podrá», «El Estado promoverá»; «El Estado garantizará», «La ley determinará»; expresiones de ambigüedad que sólo contribuyen para que el legislador impida la plena participación. ${ }^{12}$

La Constitución Política define y desarrolla el principio democrático de participación ciudadana en varios de sus artículos, comenzan-

${ }^{11}$ Mina Paz, Álvaro. (2001) Artículo «tiempos de reflexión», Volumen 6, Colombia. p. 1.

${ }^{12}$ Mina Paz, Álvaro. Agosto (2005) «Participación ciudadana en Colombia», Revista aportes andinos. 
do por el preámbulo, donde se ven los fines del constituyente, lo que debe garantizar la constitución.

En ejercicio de su poder soberano, representado por sus delegatarios a la Asamblea Nacional Constituyente, invocando la protección de Dios, y con el fin de fortalecer la unidad de la Nación y asegurar a sus integrantes la vida, la Convivencia, el trabajo, la justicia, la igualdad, el conocimiento, la libertad y la paz, dentro de un marco jurídico, democrático y participativo que garantice un orden político, económico y social justo, y comprometido a impulsar la integración de la comunidad latinoamericana, $(. . .)^{13}$

En el artículo 1 de la Constitución se evidencia implícita la democracia y la participación ciudadana, el artículo 2 de la Constitución habla de los fines del Estado por lo que inferimos que es un artículo que expresa valores en su totalidad, en él se encuentra el valor de la participación ciudadana, el artículo 3 de la Constitución trata sobre la soberanía popular, que debe ser entendida como un principio democrático, ya que si suponemos que ésta reside en el pueblo, un elemento fundamental de la democracia, el poder del pueblo, se materializa en la construcción de un marco político y jurídico donde el único legitimado para hacer leyes y construir un orden social justo es el Pueblo. ${ }^{14}$

ARTÍ́CULO 1. Colombia es un Estado social de derecho, organizado en forma de República unitaria, descentralizada, con autonomía de sus entidades territoriales, democrática, participativa y pluralista, fundada en el respeto de la dignidad humana, en el trabajo y la solidaridad de las personas que la integran y en la prevalencia del interés general. ${ }^{15}$

Los conceptos de participativa y pluralista que señala este artículo primero, tienen el propósito de garantizar el control de los ciudadanos en la actividad pública, otorgando igualdad y oportunidades, para que este vigile la actividad de la administración, pero el Estado Social de Derecho que tenemos enmarcado no ha dado las respuestas a su sociedad, no ha sido garantía para el respeto de los derechos defendidos en él, por la falta de implicación de las dos partes ciudadanos y

${ }^{13}$ Preámbulo de la Constitución Política de Colombia. 1991. p. 3.

${ }^{14}$ Medina Forero, Henry, Fonseca, José Daniel, Lozano Sánchez, Diego, Chain LEÓN, María Carolina. (2012). «Reconocimiento del principio democrático constitucional de participación ciudadana en la conformación de la Comisión Nacional Ciudadana del Estatuto Anticorrupción» Semillero de investigación ALTERIUS, Universidad Santo Tomás de Bucaramanga. p. 12.

${ }^{15}$ Artículo 1. Constitución Política de Colombia 1991. 
Estado. Los mecanismos de participación son vías que están para la defensa de los ciudadanos y como tal debieran tener un mejor tratamiento.

ARTÍCULO 2. Son fines esenciales del Estado: servir a la comunidad, promover la prosperidad general y garantizar la efectividad de los principios, derechos y deberes consagrados en la Constitución; facilitar la participación de todos en las decisiones que los afectan y en la vida económica, política, administrativa y cultural de la Nación; defender la independencia nacional, mantener la integridad territorial y asegurar la convivencia pacífica y la vigencia de un orden justo.

Las autoridades de la República están instituidas para proteger a todas las personas residentes en Colombia, en su vida, honra, bienes, creencias, y demás derechos y libertades, y para asegurar el cumplimiento de los deberes sociales del Estado y de los particulares. ${ }^{16}$

ARTÍCULO 3. La soberanía reside exclusivamente en el pueblo, del cual emana el poder público. El pueblo la ejerce en forma directa o por medio de sus representantes, en los términos que la Constitución establece. ${ }^{17}$

La participación ciudadana como un derecho fundamental, esto se ve en el artículo 40:

Todo ciudadano tiene derecho a participar en la conformación, ejercicio y control del poder político, para hacer efectivo este derecho puede (...) tomar parte en elecciones, plebiscitos, referendos, consultas populares y otras formas de participación democrática (...). ${ }^{18}$

Como se observa el derecho de participación tiene distintos escenarios en los cuales se puede hacer efectivo, como quiera que la misma norma contiene expresa la cláusula del artículo 40. CP.

«otras formas de participación democrática» que incluye diversos mecanismos para hacer prevalecer el derecho de conformar, ejercer y controlar el poder público.

Es por esto, que dentro del texto constitucional se hizo referencia al fomento de las prácticas democráticas, con el fin de incentivar la participación ciudadana desde los primeros años de vida, como lo plantea a continuación el artículo 41 de la Constitución Política. ${ }^{19}$

${ }^{16}$ Artículo 2. Constitución Política de Colombia 1991.

${ }^{17}$ Artículo 3. Constitución Política de Colombia. 1991.

${ }^{18}$ Artículo 40. Constitución Política de Colombia. 1991.

${ }^{19}$ Medina Forero, Henry, Fonseca, José Daniel, Lozano Sánchez Diego, Chain LEón, María Carolina. (2012). «Reconocimiento del principio democrático constitu- 
En todas las Instituciones de educación, oficiales o privadas, serán obligatorios el estudio de la Constitución y la instrucción cívica. Así mismo se fomentarán prácticas democráticas para el aprendizaje de principios y valores de participación ciudadana (...). ${ }^{20}$

En la Constitución se incluye el papel que deben asumir los ciudadanos en el Estado Democrático, son titulares de la soberanía y tienen la posibilidad de usar los mecanismos de participación, se ve en el artículo 95 numeral 5 de la carta.

«(...) Son deberes de la persona y del ciudadano: (...) Participar en la vida, cívica y comunitaria del país». ${ }^{21}$

El título IV de la Constitución, sobre mecanismos de participación faculta al pueblo a ejercerlos de forma directa y deliberativa, haciéndolos instrumentos de uso, se percibe como se le otorgo el derecho fundamental de participación al ciudadano, garantizando la implicación de este de una manera responsable en la participación y dando poder al legislador a crear las normas necesarias, esto se ve en el artículo 152 d. de la Constitución:

«Mediante leyes Estatutarias el Congreso de la República regulará las siguientes materias (...)

Instituciones y mecanismos de participación ciudadana.» 22

El hecho que se haga mediante leyes estatutarias hace notar la importancia del tema, debido al riguroso trámite de aprobación de este tipo de leyes.

En el artículo 270 sobre gestión y control de la cosa pública, se estipuló lo siguiente, incluyendo el principio democrático de participación ciudadana.

«La Ley organizará las formas y los sistemas de participación ciudadana que permitan vigilar la gestión pública que se cumpla en los diversos niveles administrativos y sus resultados.»23

La importancia de estos artículos es inmensa pues de ellos se parte como fundamento jurídico para crear toda la normativa de la participación ciudadana.

cional de participación ciudadana en la conformación de la Comisión Nacional Ciudadana del Estatuto Anticorrupción» Semillero de investigación ALTERIUS, Universidad Santo Tomás de Bucaramanga. p. 13.

${ }^{20}$ Artículo 41 Constitución Política de Colombia. 1991.

${ }^{21}$ Numeral 5 del artículo 95 de la Constitución Política de Colombia. 1991.

${ }^{22}$ Artículo 152.d. Constitución Política de Colombia. 1991.

${ }^{23}$ Artículo 270. Constitución Política de Colombia. 1991. 
Hasta este momento se observa que el constituyente otorgó un derecho fundamental a participar, la obligatoriedad de la instrucción democrática con el fin de garantizar la apropiación por parte del conglomerado del derecho a participar y la obligación del ciudadano de asumir su responsabilidad dentro de los espacios participativos que el orden constitucional le asigna. ${ }^{24}$

La Constitución ha sentado las bases, pero es necesario el cambio de conducta de los ciudadanos, de cultura, para defender los intereses generales, no son suficientes las reformas si falta esto. Esta Constitución ha dado paso a mayores protestas frente a la hegemonía del poder, algo que visto de una manera positiva es importante porque se ve la trascendencia de la inclusión de los ciudadanos como parte fundamental en el proceso.

«Los instrumentos de participación democrática garantizados en la Constitución no se limitan a la organización electoral sino que se extienden a todos los ámbitos de la vida individual, familiar, social y comunitaria ${ }^{25}$.

La Democracia Participativa se puede ver como un sistema que configura una forma de gobierno democrático, que sirve para observar el cumplimiento de la administración, siendo necesario la unión de los ciudadanos, la inconformidad en temas que los afecten en común, y con el respaldo y los derechos que la Constitución otorga se es acreedor de estos mecanismos, es un desarrollo que se debe a la participación ciudadana, pero es notoria la falta de actividad por parte de estos, reduciendo así una forma de defender sus derechos, ya sea por su poco conocimiento, divulgación, entendimiento y falta de conciencia por parte de los ciudadanos, de lo contrario con la participación se ejercería un control a la gestión pública y se cumpliría parte de nuestra finalidad como sociedad.

La Constitución de 1991 dio fundamento jurídico a la participación ciudadana mediante pronunciamiento de la Corte Constitucional en sentencia del 14 de abril de 1994. Esta sentencia argumenta que ${ }^{26}$ el principio de participación democrática más que un sistema de

${ }^{24}$ Medina Forero, Henry, Fonseca, José Daniel, Lozano Sánchez, Diego, Chain LEón, María Carolina. (2012). «Reconocimiento del principio democrático constitucional de participación ciudadana en la conformación de la Comisión Nacional Ciudadana del Estatuto Anticorrupción» Semillero de investigación ALTERIUS, Universidad Santo Tomás de Bucaramanga. p. 13.

${ }^{25}$ Sentencia 336 de 1994. Corte Constitucional. Colombia. p. 6.

${ }^{26}$ Cogollos, Silvia-Ramírez León, Jaime (2007) «El camino tortuoso de la participación ciudadana». Una mirada al cabildo abierto en Bogotá universitas humanística n. ${ }^{\circ} 63$ enero-junio de 2007 Bogotá-Colombia. p. 7 
toma de decisiones, es un modelo de comportamiento social y político, fundamentado en los principios del pluralismo, la tolerancia, la protección de los derechos y libertades así como en una gran responsabilidad de los ciudadanos en la definición del destino colectivo. El concepto de democracia participativa, dice la Corte, lleva ínsita la aplicación de los principios democráticos que conforman la práctica política a esferas diferentes de la electoral. Comporta una revaloración y un dimensionamiento vigoroso del concepto de ciudadano y un replanteamiento de su papel en la vida nacional. ${ }^{27}$

\section{Corte Constitucional de Colombia. Sentencia C-180/1994}

En esta sentencia se analizó la constitucionalidad del proyecto de Ley estatutaria 92/1992 Senado-282/1993 Cámara "por la cual se dictan normas sobre mecanismos de participación ciudadana»

Los mecanismos de participación ciudadana son argumentados en la Sentencia C180, como modelos de participación organizados, para ponerse en práctica buscando menos desigualdad con la participación de los ciudadanos (democracia participativa), de formas diferentes al voto.

Pronunciamiento de La Corte Constitucional en la C-180/94 sobre la democracia participativa:

No comprende simplemente la consagración de mecanismos para que los ciudadanos tomen decisiones en referendos o en consultas populares, o para que revoquen el mandato de quienes han sido elegidos, sino que implica adicionalmente que el ciudadano puede participar permanentemente en los procesos decisorios no electorales que incidirán significativamente en el rumbo de su vida. Se busca así fortalecer los canales de representación, democratizarlos y promover un pluralismo más equilibrado y menos desigual. La participación concebida dentro del sistema democrático a que se ha hecho referencia, inspira el nuevo marco sobre el cual se estructura el sistema constitucional del Estado colombiano. Esta implica la ampliación cuantitativa de oportunidades reales de participación ciudadana, así como su recomposición cualitativa en forma que, además del aspecto político electoral, su espectro se proyecte a los planos de lo individual, familiar, económico y social. ${ }^{28}$

${ }^{27}$ Sentencia No. C-180/94, Corte Constitucional, Abril 14 de 1994, Magistrado ponente: Hernando Herrera Vergara. p. 82.

${ }^{28}$ Ibídem. p. 83. 
Hay dos concepciones de la Corte con respecto al tema del Cabildo Abierto, la mayoritaria que habla sobre la importancia teórica del Cabildo y por lo tanto declaró exequible la norma, quedando esta de la manera actual en la que no tienen carácter vinculante las decisiones tomadas en estas reuniones, argumentaron que en un futuro el congreso podría por vía estatutaria reconocerle esta fuerza vinculante, cosa que no ha ocurrido en estos años.

Solo destaca la importancia de este mecanismo de manera teórica:

«Del fortalecimiento del Cabildo Abierto con su espacio propio, depende la expansión de la modalidad de participación directa en forma de asambleas generales a otros ámbitos del Estado. El cabildo abierto, como nos enseña la historia, cuando adquiere dinámica, se convierte en escenario del tratamiento popular a los problemas nacionales, regionales o locales, según el caso». ${ }^{29}$

Y la otra concepción recogida en el salvamento de voto:

Por su parte, el Salvamento parcial de voto suscrito por los Magistrados Carlos Gaviria Díaz, Alejandro Martínez Caballero, Eduardo Cifuentes Muñoz y Vladimiro Naranjo Mesa, considera que es contrario a la Constitución atribuirle al cabildo abierto un carácter meramente deliberante, pues con ello el mecanismo se confunde con el derecho de petición consagrado en el artículo 23 de la Carta, cuando debiera ser un instrumento de participación adicional, como forma de expresión de la soberanía popular. En este Salvamento expresamente se alude si bien de modo muy tangencial al efecto meramente simbólico que pueden tener este tipo de normas de participación ciudadana. ${ }^{30}$

\section{Salvamento de voto a la Sentencia N. ${ }^{\circ}$ C-180/94}

CABILDO ABIERTO-Naturaleza (Salvamento de voto)

El Cabildo Abierto es hoy en día una clara expresión de la soberanía popular local y de la democracia participativa contemporánea. De ahí su adopción en el artículo 103 la Constitución de 1991, como uno de los mecanismos de participación del pueblo en el ejercicio de su soberanía. La decisión mayoritaria de la Corte sobre este punto, acep-

\footnotetext{
${ }^{29}$ Corte Constitucional, Sentencia C-180 de 1994. p. 113.

${ }^{30}$ Salvamento parcial de voto (suscrito por los Magistrados Gaviria Díaz, Martínez Caballero, Cifuentes Muñoz y Naranjo Mesa) a la Sentencia C-180 de 1994, Óp. cit., pp. 570 y 571
} 
ta el sentido democrático y participativo de la institución pero, de manera inexplicable, limita sus alcances hasta considerar que sólo tiene efectos deliberantes. En estas condiciones, el cabildo abierto se confunde con el derecho de petición consagrado por el constituyente en el artículo 23 de la Carta. La voluntad popular de institucionalizar una vía de participación adicional, queda entonces desvirtuada por la decisión de la Corte de recortar sus alcances hasta confundir su operatividad con la de otra figura ya existente.

1. El cabildo surge como una expresión política de la vida municipal española del siglo XI. En un principio se manifestaba de manera abierta y comprendía a los habitantes de todo el territorio. Posteriormente surge el cabildo cerrado, compuesto por comisiones de pocos individuos, depositarios de poder representativo. Esta institución tuvo gran importancia durante la colonia española en América. La ley II, título X, libro IV de la Recopilación de las Leyes de Indias autorizaba la convocatoria del cabildo abierto en situaciones de gravedad extrema, que afectaban profundamente la existencia común, con el objeto de adoptar soluciones a la crisis. Durante los siglos XVII y XVIII los cabildos abiertos se constituyeron en verdaderas reuniones populares, lideradas por tribunos elocuentes, en las cuales fue germinando el espíritu revolucionario que dio origen a la independencia.

2. El cabildo Abierto tuvo lugar en aquellas situaciones de crisis cuando las instituciones previstas para resolver problemas ordinarios resultaban insuficientes. Históricamente fue una especie de manifestación del constituyente primario en el ámbito municipal. No obstante su origen medioeval, el cabildo abierto es hoy en día una clara expresión de la soberanía popular local y de la democracia participativa contemporánea. De ahí su adopción en el artículo 103 la Constitución de 1991, como uno de los mecanismos de participación del pueblo en el ejercicio de su soberanía.

3. La decisión mayoritaria de la Corte sobre este punto, acepta el sentido democrático y participativo de la institución pero, de manera inexplicable, limita sus alcances hasta considerar que sólo tiene efectos deliberantes. En estas condiciones, el cabildo abierto se confunde con el derecho de petición consagrado por el constituyente en el artículo 23 de la Carta. La voluntad popular de institucionalizar una vía de participación adicional, queda entonces desvirtuada por la decisión de la Corte de recortar sus alcances hasta confundir su operatividad con la de otra figura ya existente. 
4. Eliminados su efectos jurídicos, la única consecuencia que subsiste del texto constitucional es la nominal y, con ella, la de un eventual efecto simbólico en beneficio de la participación ciudadana, cuya utilidad es dudosa si se tiene en cuenta la producción de otro efecto simbólico paralelo al anterior, y esta vez en beneficio de la frustración y de la apatía, ocasionadas por la ineficacia de los enunciados constitucionales.

5. Las dificultades de la puesta en marcha de una institución constitucional no pueden conducir al legislador a frustrar su sentido y alcance. Es cierto que la reglamentación del Cabildo Abierto -como la de la revocatoria del mandato- plantea problemas difíciles y delicados. Sin embargo, la dificultad no es una imposibilidad -como lo demuestran otras legislaciones que contemplan la figura- y debió ser asumida -al menos por la Corte- para respetar la voluntad constituyente. ${ }^{31}$

Es el carácter deliberatorio el que le quita valor al Cabildo Abierto, ya que al no ser decisorios los compromisos que se hacen en ellos, no son de obligatorio cumplimiento, y como se observó en el análisis de las actas de los Cabildos realizados hasta el momento por el Concejo de Bogotá, se ve la falta de compromiso y cumplimiento real por parte de los representantes del gobierno en los temas que se tratan en ellos.

El Cabildo Abierto hace parte de los mecanismos democráticos concebidos para ejercer el control político frente a las instituciones estatales y las actuaciones de sus funcionarios. Por tanto, cuando los representantes de los organismos o corporaciones estatales asisten a las citaciones a Cabildo Abierto se está llevando a cabo un proceso de rendición de cuentas en algún grado correlacionadas con las problemáticas manifiestas por la ciudadanía. Es claro el entronque dado entre la teoría de la democracia participativa y el marco jurídico de la participación ciudadana en el cabildo abierto. ${ }^{32}$

Otras sentencias.

La Corte Constitucional define el principio democrático desde el punto de vista universal y expansivo:

${ }^{31}$ Ibídem. p. 220.

${ }^{32}$ Cogollos, Silvia-Ramírez León, Jaime (2007) «El camino tortuoso de la participación ciudadana. Una mirada al cabildo abierto en Bogotá» universitas humanística n. ${ }^{\circ} 63$ enero-junio de 2007 Bogotá-Colombia. p. 7. 


\section{Corte Constitucional de Colombia. Sentencia C-089 de 1994.}

(...), es suficiente para comprender que el principio democrático que la Carta prohíja es a la vez universal y expansivo. Se dice que es universal en la medida en que compromete variados escenarios, procesos y lugares tanto públicos como privados y también porque la noción de política que lo sustenta se nutre de todo lo que vitalmente pueda interesar a la persona, a la comunidad y al Estado y sea por tanto susceptible de afectar la distribución, control y asignación de poder social. El principio democrático es expansivo pues su dinámica lejos de ignorar el conflicto social lo encauza a partir del respeto y constante reivindicación de un mínimo de democracia política y social que, de conformidad con su ideario, ha de ampliarse progresivamente conquistando nuevos ámbitos y profundizando permanentemente su vigencia, lo que demanda por parte de los principales actores públicos y privados un denodado esfuerzo para su efectiva construcción. ${ }^{33}$

El principio democrático debe ser entonces de un carácter amplio que abarque todas las posibilidades de participación superando las netamente electorales, con el fin de otorgar un verdadero control y poder político a los individuos, como consecuencia del carácter expansivo del mismo. El resultado de esto es la prevalencia sustancial del contenido de los mecanismos jurídicos que establecen formas de participación ciudadana no electorales, sobre las presuntas formalidades que dilatan el acceso a procesos serios de inclusión de la sociedad civil en el control político. De lo anterior se deduce otra característica del Principio Democrático de Participación Ciudadana que es la prevalencia de lo sustancial sobre lo formal en la aplicación de normas que den vida a instituciones participativas. El Tribunal Constitucional se refiere de esta manera al desarrollo del carácter expansivo del Principio Democrático de Participación Ciudadana. ${ }^{34}$

\section{Corte Constitucional de Colombia. Sentencia C-179 de 2002.}

La democracia participativa supone una tendencia expansiva. Esta característica significa que el principio democrático debe ampliarse

${ }^{33}$ Corte Constitucional de Colombia. Sentencia C-089 de 1994. p. 10.

${ }^{34}$ Medina Forero, Henry, Fonseca, José Daniel, Lozano Sánchez, Diego, Chain LEÓN, María Carolina. (2012). «Reconocimiento del principio democrático constitucional de participación ciudadana en la conformación de la Comisión Nacional Ciudadana del Estatuto Anticorrupción». Semillero de investigación ALTERIUS, Universidad Santo Tomás de Bucaramanga. p. 15. 
progresivamente a nuevos ámbitos y hacerse cada vez más vigente, lo cual exige la construcción de una nueva cultura que debe paulatinamente implementarse en la sociedad política. Se trata pues de una maximización progresiva de los mecanismos que permiten el acceso al poder político, y el ejercicio y control del mismo, así como la injerencia en la toma de decisiones. Desde este punto de vista, la tendencia expansiva de la democracia participativa proscribe los obstáculos y trabas que impiden la efectiva realización de la democracia, y el excesivo formalismo de las normas que regulan el ejercicio de los derechos políticos. ${ }^{35}$

El artículo 95 de la Constitución habla sobre el deber que tiene el ciudadano a participar, por ende el estado debe darle las garantías y los espacios, y a la par cada persona debe tener un sentido de apropiación con responsabilidad al ejercer este derecho; la Corte Constitucional explica esto de la siguiente manera:

\section{Corte Constitucional de Colombia. Sentencia C-1330 de 2000}

Mirada desde el punto de vista de la dogmática constitucional, la participación ciudadana es un principio fundamental que ilumina todo el actuar social y colectivo en el Estado social de Derecho, y que, en relación con el régimen constitucional anterior, persigue un incremento histórico cuantitativo y cualitativo de las oportunidades de los ciudadanos de tomar parte en los asuntos que comprometen los intereses generales. Por ello mismo, mirada desde el punto de vista del ciudadano, la participación democrática es un derecho-deber, toda vez que le concede la facultad y a la vez la responsabilidad de hacerse presente en la dinámica social que involucra intereses colectivos. Esa facultad no se circunscribe a los procesos propiamente políticos, y su ejercicio debe estar adecuadamente garantizado, pues así lo exigen las mismas normas superiores. ${ }^{36}$

\section{Corte Constitucional de Colombia. Sentencia T-637/01}

\section{DEMOCRACIA REPRESENTATIVA Y DEMOCRACIA PARTICIPATIVA}

Con la Constitución de 1991 se inició constitucionalmente el tránsito de la democracia representativa a la participativa. Esta nueva

\footnotetext{
${ }^{35}$ Corte Constitucional de Colombia. Sentencia C-179 de 2002.

${ }^{36}$ Corte Constitucional de Colombia. Sentencia C-1330 de 2000.
} 
concepción de nuestra democracia implica un cambio trascendental del sistema político, cuya primera y más clara manifestación se encuentra en la manera como se comprende al ciudadano como tal. El concepto de democracia participativa es más moderno y amplio que el de la democracia representativa. Abarca el traslado de los principios democráticos a esferas diferentes de la electoral, lo cual está expresamente plasmado en el artículo $2^{\circ}$ de la Carta. Es una extensión del concepto de ciudadanía y un replanteamiento de su papel en una esfera pública que rebasa lo meramente electoral y estatal. El ciudadano puede participar permanentemente en los procesos decisorios que incidirán en el rumbo de su vida. Esto se manifiesta en varios artículos de la Carta sobre participación en escenarios diferentes al electoral.

\section{DEMOCRACIA PARTICIPATIVA-Fines}

En la democracia participativa no sólo se valora más al ciudadano sino que, en razón a ello, el sistema político puede alcanzar mayores niveles de eficiencia. Un Estado en el que los ciudadanos cuentan con el derecho de tomar parte de forma directa en las decisiones a adoptar, de controlar los poderes públicos, de calificar los resultados obtenidos para exigir responsabilidad política, es un Estado en el que probablemente se logrará satisfacer en más alto grado las necesidades de sus asociados. Dentro de ese espíritu, el artículo $2^{\circ}$ de la Carta Política enuncia como fin primordial del Estado el de «servir a la comunidad».37

\section{Ley 134 de 1994 "por la cual se dictan normas sobre mecanismos de participación ciudadana»}

Es la ley que reglamento el Cabildo Abierto, por lo tanto se debe consultar para la preparación y desarrollo de este, a lo largo del análisis de esta ley se observan las dificultades con las que el ciudadano puede encontrarse desde el principio de querer iniciar un Cabildo.

En la exposición de motivos que realizo el Gobierno, a la hora de presentar a consideración del Congreso de la República, el proyecto de ley estatutaria, vemos la importancia y el sentir que le quisieron implantar a esta Ley, basándose en el diseño Democrático que se ins-

\footnotetext{
${ }^{37}$ Corte Constitucional de Colombia. Sentencia T-637/01.
} 
tauro con la Constitución Política de 1991, en la cual los ciudadanos son los partícipes que deben hacerla efectiva.

La preparación la deben hacer los promotores (ciudadanos, concejales, ediles o sus representantes) y examinar si es el mecanismo apropiado, luego deben identificar los problemas comunes, y a continuación ya se encuentran con problemas en el momento de la planeación del mismo ya que se pide un número elevado de firmas en el artículo 82 de la ley (un número no inferior al cinco por mil del censo electoral del municipio, distrito, localidad comuna o corregimiento, según el caso) como necesarias para que el cabildo sea aceptado por la entidad respectiva y se convoque, el Cabildo es de carácter obligatorio para las juntas administradoras locales, los concejos municipales o distritales ya que en la ley expresamente en su artículo 81 indica que estas corporaciones deben realizar al menos dos cabildos por cada periodo de sesiones ordinarias, cosa que no se cumple, se podría interpretar que cualquiera de estas entidades por iniciativa propia podrían realizarlo ciñéndose a este artículo 81 en cumplimiento de la ley.

Junto con este artículo 81 de la Ley estatutaria, está la Ley 136 de 1994, "por medio de la cual se dictan normas tendientes a modernizar la organización y el funcionamiento de los municipios». La cual indica en el artículo 131 que las juntas administradoras locales (JAL), además de las funciones que les otorga la Constitución Política, ejercerán las siguientes funciones: Celebrar al menos dos Cabildos Abiertos por período de sesiones, también esta Ley 507 de 1999 «la cual modificó la Ley 388 de 1997», en su artículo 2 indica: Los Concejos Municipales o Distritales, de conformidad con lo establecido en el artículo 81 de la Ley 134 de 1994, celebrarán obligatoriamente un Cabildo Abierto previo para el estudio y análisis de los Planes de Ordenamiento Territorial sin perjuicio de los demás instrumentos de participación contemplados en la ley. Se ve cómo se ordena la celebración de cabildos, pero no se ve ninguna posible sanción por incumplir estas normas y puede que esto influya en gran parte en la ausencia de celebración de los mismos.

En el año 2013 según el archivo de la Registraduría del Estado Civil se ha activado más la participación ciudadana a nivel municipal, suponemos que por ser zonas de menor extensión territorial y por lo tanto requerirse menor número de firmas y por ende tener más facilidad a la hora de darse a conocer entre los habitantes este mecanismo, si examinamos el caso Bogotá sabemos que es una ciudad con más de 8 millones de habitantes, con 20 localidades y 1.200 barrios, por lo 
tanto si se hiciera más accesible a la ciudadanía, se fomentaría más la práctica de este mecanismo, pues vemos que la Ley se ha creado sobre una base entusiasma de darle a los ciudadanos medios de participación, pero a medida que se desarrolla se encuentran obstáculos, ya que crea restricciones y no facilita la vía que deben seguir al momento de querer convocar un Cabildo Abierto, es necesario que se convierta en una herramienta útil para la población que es parte fundamental en la Democracia Participativa. 
